\title{
DELEUZE E A QUESTÃO DA LITERARIDADE*
}

\author{
FRANÇOIS ZOURABICHVILI*
}

\begin{abstract}
RESUMO: Podemos organizar uma teoria de ensino a partir da obra e da prática pedagógica de Gilles Deleuze em torno de três temas: 1. a aula tem a ver com o que buscamos e não com o que sabemos. 2. Não sabemos por quais signos um estudante aprende ou tornase bom em alguma coisa. 3. A atividade de pensar, e também o verdadeiro e o falso relativamente a essa atividade, começam quando traçamos os problemas mesmos. Um outro aspecto, menos visível, implica os outros três, já que se joga aí o destino mesmo do discurso de Deleuze, nossa capacidade de entendê-lo, assim como a sua própria capacidade de se fazer entender. Trata-se da insistência sobre uma compreensão ao pé da letra. A literalidade é o motivo de uma pedagogia interna à filosofia, de uma pedagogia propriamente filosófica.
\end{abstract}

Palavras-chave: Literalidade. Ensino. Aprendizado. Experiência.

\section{DELEUZE AND THE QUESTION OF LITERALITY}

ABSTRACT: The work and practice of Deleuze allows us to organize a teaching theory around three themes: 1) Teaching is about what we are searching, not what we know; 2). We do not know what signs make a student learn or be good in whatever subject matter; 3. Thinking, as well whatever is true and false in this activity, begins when we establish the very problems. Though less visible, another aspect implies all of the previous ones, since what is at stake here is the very status of the discourse of Deleuze, our ability to understand it, and his own ability to make himself under-

* Tradução de Sandra Corazza e Tomaz Tadeu, que agradecem à Fabiana de Amorim Marcello a ajuda na localização das referências nas edições brasileiras. Algumas das traduções foram modificadas ligeiramente.

** Doutor em Filosofia e professor da Université Paul Valery - Montpellier III. E-mail: afz@club-internet.fr

Educ. Soc., Campinas, vol. 26, n. 93, p. 1309-1321, Set./Dez. 2005

Disponível em <http://www.cedes.unicamp.br> 
stood. I insist that we should read him literally and not metaphorically. Literality is the reason of a pedagogy internal to philosophy, of a pedagogy that is philosophical per se.

Key words: Literality. Teaching. Learning. Experience.

A e perguntarmos qual teoria de ensino se pode deduzir da obra e da prática pedagógica de Gilles Deleuze, podemos reuni-la em torno de três elementos:

1. "Ensina-se sobre o que se pesquisa e não sobre o que se sabe" (Deleuze, 1992, p. 173; cf. também Deleuze, 1988, p. 18).

2. "Quem sabe como um estudante pode tornar-se repentinamente 'bom em latim', que signos (talvez amorosos ou até mesmo inconfessáveis) lhe foram úteis para a aprendizagem?" (Deleuze, 1987, p. 22).

3. "Fazem-nos acreditar que a atividade de pensar, assim como o verdadeiro e o falso relativamente a essa atividade, não começa senão com a procura das soluções, não diz respeito senão às soluções. (...) Como se não continuássemos escravos enquanto não dispusermos dos problemas mesmos, de uma participação nos problemas, de um direito aos problemas, de uma gestão dos problemas" (Deleuze, 2000, p. 268).

Eis aí três motivos pedagógicos manifestos que, por conveniência, podem ser reagrupados em torno de um mesmo problema, o da experiência: se aprender é uma experiência que envolve todo o ser, e não a troca entre um sábio e um ignorante, o ensino ajusta-se às condições da aprendizagem, desde que ele próprio seja uma experiência; este requisito será satisfeito caso se coloque a atenção nos problemas e na diferença dos problemas. Os cursos de Deleuze constituem uma demonstração de como esses três motivos podem ser colocados em prática: na escolha dos temas, nas digressões momentâneas, nas respostas às intervenções dos estudantes.

É verdade que a aprendizagem torna-se, em Deleuze, o modelo de toda experiência, uma vez que ela se confunde com a inventividade do desejo. Essa ampliação poderia comprometer uma teoria da pedagogia "propriamente dita", ao diluí-la em generalidades demasiadamente abrangentes. Vê-se que não é assim: entre o gosto pedagógico de Deleuze e 
sua vocação de filósofo crítico, as trocas são mútuas e, provavelmente, uma está na origem da outra; a promoção transcendental do processo de aprender não se dá sem uma meditação do estudante e, depois, do professor, sobre a relação originária entre o saber e o afecto. Em vez de ser esgotado por seu arrebatamento filosófico, o sentido "próprio" da aprendizagem dele se nutre.

Esse último ponto toca no tema que será tratado aqui. Pois a caracterização da pedagogia deleuziana não seria completa se nos limitássemos à articulação sistemática dos três enunciados manifestos. Um outro aspecto, menos visível, implica os outros três, já que se joga aí o destino mesmo do discurso de Deleuze, nossa capacidade de entendê-lo, assim como a sua própria capacidade de se fazer entender. Trata-se da insistência sobre uma compreensão ao pé da letra (Deleuze \& Guattari, 1998, p. 26). ${ }^{1} \mathrm{O}$ fato é que esta compreensão não é evidente e que, alternadamente, nós a praticamos sem falar dela e falamos dela sem praticá-la. A literalidade é o motivo de uma pedagogia interna à filosofia, de uma pedagogia propriamente filosófica.

O próprio Deleuze nunca se deteve para estudar a questão da literalidade. Esta questão aflora incessantemente, tanto em suas aulas quanto em seus livros, é objeto de alguns desenvolvimentos, embora nunca seja verdadeiramente discutida. Nem por isso ela é menos decisiva, tanto para compreender Deleuze quanto para continuar fazendo filosofia hoje. Ao contrário, ela constitui uma via de acesso privilegiado a Deleuze, situandose nas antípodas do tipo de abordagem confortável, que consiste em compreender e, talvez, reutilizar os conceitos de Deleuze a partir de um campo de compreensão ou de interpretação que lhe é exterior (muitos leitores de Deleuze têm, assim, a impressão de vê-lo movimentar-se, mas eles próprios parecem continuar parados, mesmo quando gesticulam).

Talvez seja necessário levar a sério a expressão "fazer filosofia". O enunciado filosófico não é separável de um fazer, e este fazer é o desvio, o deslizamento, o deslocamento de perspectiva geral, que constitui a originalidade de um filósofo, e que não pára de repetir-se ao longo de sua obra, de modo a dar-lhe cada vez mais consistência.

Além disso, não compreenderemos um filósofo se não nos esforçarmos, ao menos por um momento, em crer no que ele diz. Mas crer não quer dizer, aqui, aderir, parafrasear, papaguear um discurso que não fomos nós que produzimos (o que Leibniz chamava de "psitacismo"). 
Crer torna-se sinônimo de fazer. Suponhamos, pois, que compreender Deleuze seja fazer o que ele faz, por meio do que ele diz ou escreve. Veremos, mais adiante, as razões de chamarmos de "crença" este fazer inseparável do dizer, com base no que o próprio Deleuze dizia sobre a crença, no fim de sua vida.

Crer no que o filósofo diz é, pois, fazer com ele o que ele faz quando enuncia, não separar nunca seus conceitos do desvio, do deslizamento ou do deslocamento, dos quais eles são, por assim dizer, os casos. Isso supõe que o próprio fazer seja enunciado, indicado em palavras. O filósofo faz ao dizer, mas porque ele diz o que faz. É preciso que ele diga o que faz, não apenas para nos indicar isso, mas também porque fazer, em filosofia, não tem outro elemento a não ser a linguagem: trata-se de uma mudança de prática da linguagem.

Compreende-se, então, o que entendemos por via de acesso privilegiado a Deleuze: uma via de acesso àquilo que nele há, ao mesmo tempo, de desconcertante, de difícil e, até mesmo, de problemático. Para mim, a filosofia de Deleuze não é evidente nem reconfortante. A razão de meu interesse por ela é bem outra: ela não me deixa tranqüilo. Esta observação não objetiva atrair a atenção para o meu caso em especial, mas tenta definir uma atitude filosófica: uma filosofia não é interessante, a não ser por seus aspectos desconcertantes, ao mesmo tempo estranhos e atraentes. Se não fosse assim, ela se tornaria uma doutrina, um signo de reconhecimento para uma comunidade de fiéis. É por isso que não é preciso encobrir as contradições aparentes do filósofo que se ama; ao contrário, é preciso partir delas e não parar de confrontá-las; ver aí não aporias definitivas, tal como faria alguém dedicado a refutá-las, mas o signo seguro de uma perspectiva incomum.

Essa via de acesso privilegiado é a literalidade. Com efeito, quando Deleuze diz o que faz, ele diz: escrevo literalmente. Pode-se considerar essa declaração como sendo provocadora, contraditória, uma vez que a maior parte dos conceitos que o tornaram famoso tem justamente o aspecto de metáforas: "máquina desejante", "máquina de guerra", "ritornelo", "cristal do tempo", "linha de fuga”, "desterritorialização", "distribuição nômade", "rizoma" etc.

O próprio Deleuze estava consciente disso. Daí esse ritornelo, quase toda vez que ele introduz um conceito: "não se trata de uma metáfora..., não se trata de uma metáfora...”. Em outros termos, ele nos pede 
para crer que não se trata de uma metáfora, para crer no improvável - a saber, que ele escreve literalmente. Crer no que ele diz, fazer o que ele faz é, pois, isso: tentar compreender seus conceitos como não sendo metáforas; embora seja evidente que as palavras não são usadas de acordo com aquilo que chamamos de seu sentido "próprio".

Exigimos, certamente, elementos que justifiquem esse tipo de afirmação. Esses elementos são numerosos em Deleuze e convergem para aquilo que, para ele, era essencial ao final de sua vida: a imanência, a exterioridade das relações, a crença, a escrita. É evidente que se a imanência é uma prática, e se o elemento da filosofia é a linguagem, então uma filosofia da imanência define-se por uma certa prática da linguagem: em Husserl, ela se chama descrição; em Deleuze, escrita literal. Não é a mesma coisa, pois, no sentido de Deleuze, a escrita literal não tem, propriamente, objeto, nem visa a nada, mas constrói alguma coisa. Nova contradição aparente, pois a literalidade é, em princípio, dada, e não algo a ser construído.

Tentemos, pois, crer em Deleuze, e ver o que ganhamos filosoficamente com isso. Tomemos quatro exemplos de enunciados deleuzoguattarianos: "Nós somos feitos de linhas"; "O cérebro é uma árvore"; "O inconsciente é uma fábrica"; "O pequeno Hans [o menino que foi paciente de Freud] devém cavalo". E partamos da hipótese de que esses enunciados perdem todo sentido se neles vemos metáforas; ou de que, se eles têm um sentido, é ao custo de uma compreensão literal.

Comecemos por uma clarificação: Deleuze não é contra a metáfora. Ele não é o tipo de pessoa que critica os filósofos por abusarem da metáfora, em vez de utilizar as palavras em seu sentido próprio. Os filósofos analíticos têm o costume de reprovar duas coisas na filosofia dita "continental", em particular, a francesa: não argumentar e contentar-se, na maior parte do tempo, com metáforas. Deixemos de lado o primeiro critério, muito vago, uma vez que há várias maneiras não convencionais de argumentar. Apenas o segundo nos interessa aqui.

Sem dúvida, os filósofos analíticos admitem a utilização de metáforas em filosofia: Davidson, por exemplo. O próprio Wittgenstein, o grande inspirador, não parava de utilizar metáforas. Mas a questão não está aí. Ela está na possibilidade, sempre sustentada por esses filósofos, de distinguir entre um discurso metafórico e um discurso não metafórico, entre o poético e o científico, entre o falar ordinário e a retórica meta- 
física que engendra os entia rationis. Wittgenstein, por exemplo, faz uma distinção entre as proposições que designam estados de coisa do mundo e as proposições filosóficas que se mantêm no limite da linguagem e do mundo, e cuja função é a de indicar o que fazer com a linguagem.

O núcleo da dificuldade é a questão do domínio próprio da filosofia. $\mathrm{O}$ que caracteriza um discurso próprio, literal no sentido de próprio, é que as palavras aí designam seus referentes usuais. Por muito tempo, os filósofos fizeram metáforas, que justificavam pela necessidade de designar coisas para as quais não havia palavras, pois as palavras designam coisas físicas, enquanto a filosofia se ocupa de coisas metafísicas. Eles utilizavam, assim, o que a retórica chama de catacrese. São exemplos de catacrese: "ver", "elucidar", "compreender", "idéia”. Em um determinado momento - por exemplo, com Nietzsche ou com Wittgenstein -, essas pretensas entidades metafísicas passam a ser vistas como puros efeitos do poder metafórico da linguagem. Desde então, os conceitos da filosofia ficam ameaçados de não se referir a mais nada. A questão que se coloca é célebre: para que serve a filosofia se ela não tem objeto próprio? Resposta de Wittgenstein: para lutar precisamente contra a tendência perpétua da linguagem a restituir um domínio próprio ao filósofo. É o ponto de vista pragmático e não metafísico que autoriza a filosofia a produzir metáforas, isto é, a utilizar expressões que não têm referência no mundo.

Voltemos agora a Deleuze: quando ele diz "não faço metáforas", isso não significa evidentemente que ele milita por um discurso próprio que seja contra a utilização das metáforas. Tampouco, ele pretende que suas metáforas filosóficas sejam catacreses, uma vez que sua intenção não é restaurar as referências metafísicas. Ele tem dúvidas sobre a validade do próprio conceito de metáfora e, em consequiência, sobre a divisão supostamente originária entre o próprio e o figurado. Em outros termos, ele contesta a dualidade sobre a qual se construiu, desde sempre, o conceito de metáfora: a utilização de um termo em seu domínio próprio e a utilização desse mesmo termo fora de seu domínio. Ele critica essa dualidade por subordinar o pensamento à ordem da mimesis, como se pode ver em Aristóteles: o conceito de metáfora supõe a classificação natural, e o ato humano de classificar aparece, na melhor das hipóteses, como uma duplicação. Ora, a experiência não justifica absolutamente tal divisão natural das significações.

O núcleo dessa crítica está muito próximo daquilo que Derrida, por sua vez, afirmou a respeito da metáfora (Cf. Derrida, 1972 e 1987). Deleuze e Derrida têm em comum o fato de pensar que uma significa- 
ção está, desde sempre, já contaminada por uma outra. Mas as respectivas problemáticas, assim como as suas conseqüências, são diferentes. Em uma palavra, o que interessa a Derrida é que uma significação não tem, nunca, delimitação precisa (de modo que ele não crê no conceito de conceito; o qual, ao contrário, Deleuze tanto estima); o que interessa a Deleuze é a idéia de que as contaminações mudam, e a necessidade de pensar os espaços dessas contaminações móveis, que é também o espaço no qual nossa experiência se estrutura e se transforma.

Tentemos dizê-lo mais claramente: somos convidados agora a pensar esses encontros entre duas significações - que, de acordo com o conceito de metáfora, deveriam ser pensados a partir da atribuição de um domínio próprio a cada um -, na ausência de qualquer atribuição prévia e, conseqüentemente, para além da divisão entre a utilização própria das palavras e a sua utilização figurada. Se eu digo "o cérebro é uma erva", Aristóteles me explicaria que a palavra "cérebro" tem uma significação ligada, a priori, a um certo domínio de coisas, o mesmo ocorrendo com a palavra "erva"; e que eu tento exprimir obliquamente alguma coisa sobre o cérebro, ao transportar a palavra "erva" para fora de seu domínio próprio. Ele acrescentaria que a operação é legítima se, com isso, coloco em evidência uma similitude. O pressuposto é, pois, que as significações são separadas, mas aparentadas: há, entre elas, semelhanças naturais.

Já Deleuze daria uma explicação diferente: "o cérebro é uma erva" não deve, certamente, ser tomado no sentido próprio, pois está claro, para todos, que o cérebro não é um vegetal. Mas é duvidoso que eu tenha uma idéia do cérebro antes desse tipo de encontro estranho. Ou, então, essa idéia é do tipo: "o cérebro é uma árvore". Deleuze quer dizer que, nos dois casos, não se trata da mesma experiência do cérebro: nem da mesma concepção neurológica, nem da mesma relação vivida com o cérebro. Por muito tempo, acreditou-se que, uma vez que o cérebro era o órgão central, ele próprio deveria ser centralizado, como uma árvore. Os dados da neurologia dos últimos trinta ou quarenta anos nos fazem crer, ao contrário, que o cérebro é um sistema a-centrado, uma multiplicidade, cujas conexões são probabilísticas e não-predeterminadas. A grande diferença relativamente à interpretação de Aristóteles é que, por mais que eu designe alguma coisa com o nome de cérebro, esta coisa não adquire sentido senão relativamente a uma outra: o cérebro sozinho, como objeto indeterminado, não é nem árvore nem erva; não adquiro uma idéia do 
cérebro ou não tenho a experiência do cérebro, a não ser numa relação com a árvore ou com a erva, ou - por que não? - com alguma outra coisa.

Tudo isso exigiria maior detalhamento; entretanto, temos já elementos suficientes para daí extrair um certo número de proposiçōes e para entrever, finalmente, o que quer dizer "literalidade" em Deleuze. Essas proposições são em número de três:

1. Não existe sentido ou experiência a não ser na base de uma relação. As relações de que se trata aqui não são objetos empíricos, subordinados às condições da experiência; elas próprias são as verdadeiras condições da experiência, mas condições temporárias, móveis, manejáveis. De modo tal que é preciso dizer sobre essas relações que são "exteriores a seus termos", segundo uma tese que Deleuze sustentou do primeiro ao último livro.

Vê-se aí a razão pela qual Deleuze sentia-se filosoficamente mais anglo-americano do que francês. Mas, sobretudo, se a literalidade de enunciados - tais como "o cérebro é uma erva" (em vez de uma árvore), "o inconsciente é uma fábrica” (em vez de um teatro), etc. - consiste em decifrálos como relações entre dois termos iguais e não como um julgamento de atribuição que relaciona um predicado a um sujeito; então a cópula "É" adquire o sentido de "E". Define-se, assim, a orientação fundamental da filosofia de Deleuze: extinção do ser em prol da relação (ou, ainda, do devir). Além disso, todos os que falam de ontologia, a propósito de Deleuze, cometem um total disparate ou não sabem o que significa ontologia.

2. A afirmação dessas relações, enquanto elas organizam a experiência, estrutura um certo campo problemático, e recebe o nome de crença.

Este ponto exige duas observações. De um lado, a crença não depende, de forma alguma, da representação ou de um estado intencional (considerando-se essa diferença importante, poder-se-ia fazer uma comparação com o conceito de "background" em Searle, 1983, cap. 5). Por outro lado, a crença não tem nada a ver com um ato de fé pré-racional: Deleuze inscreve-se em uma tendência inaugurada por Hume, que inverte a relação entre o conhecimento e a crença. Mas em quê "o cérebro é uma erva" é semelhante ao hábito, na acepção de Hume, isto é, à repetição da associação $\mathrm{AB}$, chegando ao ponto em que dado $\mathrm{A}$, eu creio que $\mathrm{B}$ também ocorre? Esta frase, que encontramos em três ou quatro livros de 
Deleuze, funciona, para utilizar um termo dele próprio, como um ritornelo: uma relação desconcertante, mistura de sedução e de estranheza, que não pára de voltar ao espírito do pensador como um problema, como $o$ problema, a partir do qual um objeto físico tal como o "cérebro" adquire sentido. Crer que o cérebro é uma erva é um novo horizonte, tanto para a neurologia quanto para a filosofia. Crer não tem nada a ver com formular uma hipótese a propósito de uma essência, cuja revelação se situaria no infinito do processo de conhecimento. Crer é um acontecimento, uma síntese passiva, um ato involuntário, que se confunde com a abertura de um novo campo de inteligibilidade.

3. Desde logo, a experiência é sempre cristalina: por "cristal", Deleuze entende a estrutura de toda visão enquanto ela escapa ao "clichê", isto é, a reconhecimento orientado para a ação, que faz com que saibamos, sempre, antecipadamente, com o que temos que nos enfrentar e como nos comportar a respeito. Seja o exemplo do filme de Rosselini, Europa 51. A heroína, assim como todos, sabe o que é uma fábrica. Em outros termos, a fábrica tem um lugar no horizonte de seus possíveis: enquanto uma grande burguesa, ela sabe reconhecer um operário, sabe que ele não pertence ao mesmo mundo que ela, etc. Mas eis que um acontecimento de família desarranja sua vida e seu espírito bem arrumados. Ela vai, um dia, a uma fábrica, fica transtornada, e volta para casa dizendo: "acredito ter visto condenados". Deleuze comenta: não se trata de um sonho. Ao contrário, ela se afastou, pela primeira vez, dos clichês que a dispensavam, até então, de ver a fábrica. Trata-se, pois, da visão renovada de uma experiência da fábrica: ela viu a fábrica e a viu como uma prisão. Vemos a idéia de uma relação primitiva que condiciona a experiência. Em outros termos, a fábrica só começa a fazer sentido, para essa senhora, como prisão (ela teria podido fazer sentido como outra coisa, mas não é esta a questão). Deleuze conclui que ver é de natureza cristalina; se, por cristal, entendemos a relação essencial entre um termo atual (aqui, a fábrica e seus operários; no exemplo anterior, o cérebro) e um termo virtual (os condenados, a prisão; no exemplo anterior, a erva). Contrariamente à metáfora, não há redobramento, de maneira tal que uma coisa significa uma outra, mas desdobramento; a "coisa mesma", como diria Husserl, é essa relação ne- 
cessária entre um dado e um termo não-dado. Deleuze pode, então, concluir que a visão da senhora é literal, embora seja dupla, e que ela tem a aparência de combinar um termo próprio e um termo figurado (Deleuze, 1999, p. 10; p. 32; p. 60-62). Ou ainda, "o cérebro é uma erva" é literal, uma vez que o sentido de cada um dos dois termos não é separável de sua relação com o outro (esta reciprocidade é, talvez, mais difícil de perceber, embora Deleuze e Guattari insistam nessa característica voltarei a isso na conclusão).

Essa idéia de relação necessária entre um dado e um não-dado corresponde perfeitamente àquilo que Hume chamava de "crença". Compreende-se, a partir de agora, que sentido tem, em Deleuze \& Guattari, o apelo a uma leitura literal, especialmente a propósito de um romance. Pois, ainda aí, poderíamos ter o sentimento de uma contradição aparente: de um lado, eles se opóem a toda leitura metafórica ou simbólica, que consiste em "interpretar", isto é, a nos explicar que o verdadeiro sentido do que lemos não é o sentido literal, mas uma significação escondida (de modo tal que, como eles próprios dizem, "tudo vale, sempre, por uma outra coisa", e esta é uma das críticas fundamentais que eles dirigem à psicanálise ${ }^{2}$ ); por outro lado, é evidente que o que eles retêm do Moby Dick, de Herman Melville, não é uma simples história de caça à baleia, que termina mal por causa de um capitão caprichoso. Desaparece, assim, a contradição aparente: crer num sentido próprio e num sentido figurado é, finalmente, manter o conteúdo fictício e a suposta mensagem simbólica em uma relação de indiferença mútua. Na realidade, a ficção não se engendra e não se desenvolve a não ser como o instrumento de uma experimentação afetiva, de uma exploração dos pontos sensíveis da vida. Além disso, a ficção de um grande romancista não se opõe à realidade. Ao contrário, ela é a versão atual de um devir ou de uma visão, de um "cristal" no sentido anteriormente definido. A outra versão é constituída pelas intensidades percorridas. Essa dualidade atual-virtual é primitiva, irredutível: é ela, vamos repetir, que merece o nome de literalidade, em desacordo com a concepção usual de literal, que não é outra coisa que o próprio em sua oposição ao figurado. ${ }^{3}$

Voltemos, para concluir, à questão apresentada anteriormente como sendo o núcleo da dificuldade: a do domínio próprio da filosofia. Para Deleuze, o que é próprio da filosofia não é um objeto, mas uma prática. Seja o enunciado "nós somos feitos de linhas": no sentido pró- 
prio, não quer dizer nada. As linhas de um geômetra ou de um pintor não podem servir de predicado para o sujeito homem, considerado como um corpo e como um espírito. Nessa base, só se pode concluir que se trata de uma metáfora, filosoficamente confusa. Tudo muda se compreendermos que o âmbito do enunciado é crítico ou transcendental, no sentido kantiano, e não metafísico: com efeito, "linhas" consiste numa categoria do pensamento da experiência, num conceito diferenciado que permite uma decifração clínica da existência como tal. "Nós somos feitos de linha" é, pois, um desses atos involuntários que invocamos anteriormente; uma dessas crenças que abrem um horizonte de inteligibilidade, e não que desencaminham o espírito como faria uma superstição. Nesse exato momento, não mais compreendemos "nós" independentemente da significação "linhas"; e, de maneira recíproca, o que costumamos designar como linhas não será mais compreendido separadamente da relação com a nossa existência: daí o interesse de Deleuze \& Guattari por uma vitalidade não-orgânica da "linha abstrata" nas artes.

A filosofia é, pois, propriamente filosófica enquanto pensamento da experiência ou, o que vem a dar no mesmo, enquanto pensamento da imanência. Não tendo objeto, ela não tem que fazer qualquer descrição; e é por isso que encontramos em Deleuze poucos elementos de descrição do campo da experiência pura, que ele chama de "plano de imanência". Com efeito, se este campo é constituído por relações, não o atingimos senão nos tornando capazes de amarrar essas relações, isto é, se escrevemos e falamos literalmente. Em outros termos, a "coisa mesma" é a experiência enquanto ela se faz; é o devir, sempre singular, antes que o ser em geral. A "coisa mesma” é, assim, sua propriedade sem significação: nós a atingimos no momento em que as significações ficam em suspenso, quando sabemos levar a enunciação a uma de suas relações desconcertantes, mais profundas que qualquer teoria, que se afirmam obstinadamente no pensamento e a forçam a entrever novas possibilidades de pensar e de viver.

Não é fácil entender literalmente enunciados tais como "o inconsciente é uma fábrica”, "o cérebro é uma erva”, "o pequeno Hans devém cavalo", "nós somos feitos de linhas". É, entretanto, sob essa condição, que um conceito como plano de imanência começa a adquirir consistência, uma vez que ele se define como a transversal de todos os domínios tidos como próprios, em que tudo pode entrar em relação com tudo (e não em que tudo se assemelha a tudo, como diz Davidson [1984, última parte, "Limits of the Literal"]). 
Muitos lugares, notoriamente aporéticos da filosofia, mereceriam ser reconsiderados sob o ângulo da literalidade assim compreendida: especialmente a relação espírito-corpo e o difícil estatuto da música. Mas partimos do problema específico da pedagogia. A metodologia, a epistemologia, tais como as praticamos na universidade, ficam atravancadas pela divisão entre o próprio e o figurado, que reduplica, de alguma maneira, a repartição administrativa dos domínios ou das disciplinas - e que aí encontra, para dizer a verdade, seu reforço mais garantido. Tratase do velho "conflito das faculdades" de que falava Kant. Por outro lado, no entanto, todos os grandes sábios afirmam o quanto a invenção, isto é, a vitalidade da cada disciplina, se nutre do sonho ou, dito de outra forma, do livre tráfico das significações fora de seus domínios iniciais de aplicação. Explica-se, ao mesmo tempo, que a metáfora não vale nada, uma vez que ela não passa de metáfora, mas que o próprio aí se alimenta, cada vez que ele se ultrapassa e se transforma. Não se sabe mais se o próprio é primeiro, a figura não sendo mais que uma extensão ilegítima e, de toda maneira, estéril; ou se é a figura que é primeira, e o próprio aí se re-engendra periodicamente, no ruído das legitimidades. Uma pedagogia do pensamento, uma ars inveniendi para os dias de hoje, passa, talvez, pelo abandono do conceito de metáfora e pela exploração de uma problemática, em que o livre trabalho de figuração não se separa da literalidade.

Recebido em maio de 2005 e aprovado em julho de 2005.

\section{Notas}

1. Cf. "Falamos literalmente" (Deleuze; Guattari, 1998, p. 26); Deleuze; Guattari, 1999, p. 74: “(...) falo literalmente”; Deleuze, 1999, p. 255: “(...) reencadeamento sobre a imagem literal"; Deleuze, 1999, p. 220: "É preciso falar e mostrar literalmente (...)"; Deleuze, 2003, p. 199: "Todas as imagens são literais, e devem ser consideradas literalmente". Cf. também a aula de 17 de maio de 1983 ("Falar é falar literalmente, "eu falo literalmente", "é preciso falar literalmente"), a aula de 15 de janeiro de 1985 ("Se vocês falarem e mostrarem, vocês falarão e mostrarão literalmente, ou então simplesmente não mostrarão. Ou será literal ou não será nada", "falo literalmente ou simplesmente não falo", "O que isto quer dizer, este 'tudo é literal?' Tudo é tomado ao pé da letra...") etc (Para as aulas, cf. www.webdeleuze.com). Mais geralmente, Deleuze não pára de repetir que seus conceitos não são metáforas - a que faz eco a enorme freqüência da expressão "ao pé da letra", sempre acentuada ou martelada, em seu discurso oral.

2. Ao contrário, "se a linha de fuga é como um trem em marcha, é porque nela se salta linearmente, pode-se enfim falar aí 'literalmente', de qualquer coisa, talo de erva, catástrofe ou 
sensação, em uma aceitação tranqüila do que acontece em que nada pode mais valer por outra coisa" (Deleuze, 1999, p. 70).

3. Poder-se-ia confrontar o conceito deleuziano de cristal com o conceito de "ver-como", em Wittgenstein (o famoso pato-coelho). Cf. Philosophical Investigations. (1993).

\section{Referências bibliográficas}

DAVIDSON, D. Inquiries into Truth and Interpretations. Oxford: Oxford University Press, 1984.

DELEUZE, G. Proust e os signos. Trad. de Antonio Carlos Piquet e Roberto Machado. Rio de Janeiro: Forense Universitária, 1987.

DELEUZE, G. Diferença e repetição. Trad. de Luiz Orlandi e Roberto Machado. Rio de Janeiro: Graal, 1988.

DElEUZE, G. A imagem-tempo. Cinema 2. Trad. de Eloisa Araújo Ribeiro. São Paulo: Brasiliense, 1999.

DELEuZE, G. Conversaçôes. Trad. de Peter Pál Pelbart. Rio de Janeiro: Editora 34, 1992.

DELEUZE, G. Deux régimes de fous. Texts et entretiens, 1975-1995. In: Lapoujade, D. (Org). Paris: Minuit, 2003.

DELEUZE, G.; GUATTARI, F. Mil platôs: capitalismo e esquizofrenia. Trad. de Aurélio Guerra Neto, Ana Lúcia de Oliveira, Lúcia Cláudia Leão e Suely Rolnik. Vol. 3. Rio de Janeiro: Editora 34, 1999.

DELEUZE, G.; PARNET, C. Diálogos. Trad. de Eloisa Araújo Ribeiro. São Paulo: Escuta, 1998.

DERRIDA, J. La mythologie blanche. In: DerridA, J. Marges de la philosophie. Paris: Minuit, 1972.

DERRIDA, J. Le retrait de la métaphore. Poésie, Paris, n. 7, p.103-126, 1978. Reimpresso In: Derrida, J. Psyché: Inventions de l'autre. Paris: Galilée, 1987.

SEARLE, John R. Intentionality: An Essay on the Philosophy of Mind. Cambridge: Cambridge University Press, 1983.

WITTGENSTEIN, L. Philosophical investigations. Trad. ingl. G.E. Anscombe. Oxford: Blackwell, 1993. $3^{\text {a }}$ Ed. 